\title{
Devletin Yükseköğretim Öğrencilerine Yönelik Yaptığı Karşılıksız Harcamalarının Mali Boyutu
}

\author{
DOI: $10.26466 /$ opus. 680225
}

\author{
Şefika Şule Erçetin* - Sait Akbaşl1 ${ }^{* *}$-Ercan Baysülen *** \\ * Prof, Hacettepe Üniversitesi, Eğitim Yönetimi, Ankara/Türkiye \\ E-Posta: ssule@hacettepe.edu.tr \\ ORCID: $0000-0002-7686-4863$ \\ ** Prof, Hacettepe Üniversitesi, Eğitim Yönetimi, Ankara/Türkiye \\ E-Posta: sakbasli@hacettepe.edu.tr \\ ***Yönetici, MEB, İzmir/Türkiye \\ E-Posta ebaysulen@gmail.com \\ ORCID: $\underline{0000-0002-4695-5123}$
}

$\ddot{O} z$

Yükseköğretim, devletler tarafindan vatandaşlarına sunulması zorunluluk arz etmeyen yarı kamusal maldır. Ekonomik getirisinin yüksek olması sebebiyle bireylerin yükseköğretim hizmeti alması için devlet, yükseköğretim hizmeti vermekte ve bu hizmetin yükünü biraz hafifletebilmek adına özel sektörün de yükseköğretime desteğini teşvik etmektedir. Dünyanın pek çok ülkesinde de yükseköğretim ă̆ırlikl olarak kamu sektörünün desteğiyle sürdürülmektedir. Dünya ülkeleri temel ekonomileri, kültürleri ve politik sistemleri açısından birbirlerinden oldukça farklı olmalarına rağmen yükseköğretimin finansmanı konusunda ülkeler arasında büyük benzerlikler bulunmaktadır. Dünyadaki egemen tema, yükseköğretim kurumlar ile aileleri etkileyen, neredeyse tüm ülkeler tarafindan politik hedefleri karşılamak için uygulanan bu eğitimde ciddi bir kemer sıkma politikası mevcuttur; çünkü yükseköğretim, özellikle araştırma üniversiteleri oldukça maliyetlidir ve bu kurumlara olan talep her yıl artmaktadır. Artan bu maliyetler ülkeleri; yükseköğretimin kamu gelirleri, aile katkıları ve hayırseverlerin bir kombinasyonu ile finanse edilmesi gerektiği şeklindeki anlayışa yöneltmektedir. Bu çalışmada dünya ülkelerinde ve Türkiye'de yükseköğretimde harcamaların bütçe içindeki yerini ve dünyada yükseköğretime ayrılan payı belirlemek amacıyla alanyazın taraması gerçekleştirilmiştir. Erişilen çalışma bulguları değerlendirilerek, dünya ülkelerinde ve Türkiye'de bütçeden yükseköğretime ayrılan pay tartışllmiştır.

Anahtar Kelimeler: yükseköğretim, finansman, kamu harcaması 


\title{
Financial Aspects of Unpaid Spending by the State for Higher Education Students
}

\begin{abstract}
Higher education is a semi-public property which does not have to be presented by the state. However, because the state has a high level of income for education, the state undertakes this burden for individuals to receive higher education, and provides higher education and encourages the private sector to support higher education in order to alleviate some of its burden. In many countries of the world, higher education is supported by public sector. Although the countries of the world are quite different from each other in terms of their basic economies, cultures and political systems, there are many similarities between countries in the financing of higher education. The dominant theme in the world is a serious austerity policy that affects higher education institutions and families, and is implemented by almost all countries to meet policy targets, because higher education, especially research universities, is quite costly and enrolment is increasing every year. These costs increased countries; it leads to the understanding that higher education should be financed by a combination of public revenues, family contributions and philanthropists. In this study, the countries of the world and their place within the budgets of higher education expenditures in Turkey and investigate literature was conducted to determine the share allocated. Within the scope of the literature review, studies on higher education expenditures, higher education finance and statistical data have been tried to be reached. Results are evaluated and OECD countries and share of the budget allocated to higher education in Turkey was discussed.
\end{abstract}

Keywords: higher education, financing, public expenditure 


\section{Giriş}

Ekonomik kalkınmada beşeri yatırımın önemi büyüktür. İktisadi kalkınmanın dinamosu büyümedir ve büyüme üretim faktörlerinin etkin kullanılmasını gerekli kılar. Üretim faktörlerini yöneten ve bir araya getiren esas unsur insandır. Büyüme sürecinde, insan faktörünün nicel ve nitel olarak eğitilmesi, büyümenin ve kalkınmanın temel dinamiğidir. Bu nedenle ülkeler, mevcut insan gücünü daha nitelikli hale getirmek adına eğitimde, kendi hazinelerinden bazı harcamalar yapmaktadır. Söz konusu harcamalar burs, öğrenim kredisi şeklinde doğrudan parasal olarak yapılabilirken, diğer taraftan yükseköğretim öğrencilerinin toplu taşıma araçlarından, devlet tiyatrolarından, okul yemekhanesinden ve devlet yurtlarından çok düşük bedellerle yararlanabilmesi şeklinde de olmaktadır. Yapılan bu harcamalara ekono$\mathrm{mi} /$ maliye yazınında transfer harcamaları adı verilmektedir. Bu harcamaların milli gelirde herhangi bir artış yaratmadığı da bilinmektedir; ancak devletlerin bu harcamaları yapmasının altında iki amaç bulunmaktadır. Bunlardan birincisi sosyal devlet anlayışının getirdiği korumacılık politikasıdır; diğeri ise yapılan bu tarz harcamalar ile öğrencilerin eğitim öğretim sürecini tam ve sorunsuz tamamlamasını sağlamaktır. Devletlerin bu amaçlarının alt metninde yatan ana unsur ise nitelikli insan gücü yetiştirerek bu insan gücünün mezuniyet sonrası ülke ekonomisine daha nitelikli katkılar sunmasıdır. Ekonomi/maliye yazınında dışsallık olarak adlandırılan bu katkı; yükseköğretimle gelecekte olumlu etki yaratacak ve muhtemel işsizlik ya da hırsızlık gibi sosyal, üretim açığı gibi ekonomik olumsuzlukları bertaraf edecektir.

Yükseköğretim hizmeti devlet tarafından sunulması zorunluluk arz etmeyen yarı kamusal maldır. Buna rağmen devlet için getirisi yüksek bir eğitim olması sebebiyle bireylerin yükseköğretim hizmeti alması için devlet bu yükün altına girmekte, yükseköğretim hizmeti vermekte ve bu hizmet yükünü biraz hafifletebilmek adına özel sektörün de yükseköğretime desteğini teşvik etmektedir. Dünyanın pek çok ülkesinde de yükseköğretim kamu sektörü destekli olarak sürdürülmektedir (Akça, 2012). 


\section{Eğitimde Dışsallık}

Dışsallık bir ekonomik karar biriminin diğer bir ekonomik karar birimini fiyat dışı bir yolla etkilemesidir (Batı, 2017). Üretim ve tüketim faaliyetinin sonucunda dış fayda doğarsa pozitif dışsallıktan, dış zarar (dış kayıp) doğarsa negatif dışsallıktan söz edilir (Bulutoğlu, 2008, s.287). Dışsallıklar devletin ekonomiye müdahale etmesi açısından geçerli bir gerekçe oluşturmaktadır (Pehlivanoğlu, 2011).

Dışsallık kavramı ilk kez iktisatçı Alfred Marshall tarafından ortaya atılmış ve bir endüstri içerisindeki gelişme şartlarına bağlı olarak firmaların elde ettikleri faydalar şeklinde tanımlanmıştır (Stiglitz, 1994, s.261). Devletler eğitim hizmetlerinde doğrudan ya da dolaylı olarak yer almaktadır bu nedenle eğitim de dışsallık konusunda önemli bir potansiyele sahip hizmet türüdür.

Pigou ise refah ekonomisiyle dışsallıklar arasındaki ilişkiyi ortaya koymuştur (Akdoğan, 2005, s.53). Pigou ekonominin sosyal üretim düzeyi ile ekonomik refah arasında doğru yönlü bir ilişki olduğunu ve sosyal tatmine ulaşmanın refahın artmasına bağlı olduğunu ifade etmektedir (Stiglitz, 1994, s.262). Eğitim de doğrudan tüketim dışsallığı sağlayarak refah artışı gerçekleştirmektedir (Bauer and Vorell, 2010, s.5).

\section{Genel Olarak Kamu Harcaması}

Kamu harcamaları en genel anlamda, toplumsal ihtiyaçların karşılanması amacıyla devlet tarafından yapılan harcamalardır (Pehlivanoğlu, 2011). Kamu harcamaları daha önceleri, devletin sadece asli görevlerini yerine getirmek için yapmış olduğu harcamalarken, küreselleşmeyle birlikte devlet anlayışı ve devlete yüklenen görevler ve dolayısıyla kamu harcamaları da değişmiştir. İktisadi büyümenin sağlanması ve toplumsal refahın artırılması için devlete yeni ve farklı sorumluluk lar yüklenmiştir (Pehlivanoğlu, 2011). Özellikle 1929 ekonomik krizinden sonra kamu harcamaları üzerinde daha çok durulmuş ve 1950'li yıllardan itibaren kapsamlı çalışmalar yapılmıştır. Bu süreçte devletin ekonomiye müdahale boyutunun ne olacağı ve yöntemlerinin neler olacağı en çok tartışılan husus olmuştur (Bulutoğlu, 2008). İkinci Dünya Savaşından sonra az gelişmiş ve gelişmekte olan ülkelerde devletin ekonomik faaliyetleri ve özel sektör için düzenleyici rolünün giderek 
arttı̆̆ dikkat çekmektedir. Günümüzde kamu harcamaları; kamu otoriteleri tarafından, sosyal ve ekonomik hayata müdahale etmek ve toplumun ihtiyaçlarını karşılamak için belirli kurallara göre yapılan harcamalar şeklini almıştır (Nadaroğlu, 2000). Kamu harcamalarını dar ve geniş anlamda ikiye ayırmak mümkündür.

\section{Dar Anlamda Kamu Harcamalar}

Merkezi yönetim bütçe kapsamındaki idareler tarafından gerçekleştirilen hizmetler dolayısıyla yapılan harcamalardır. Devletin para halinde yaptığ harcamalardır (Stiglitz, 1994). Bütçede ve bütçe ile alakalı diğer hesaplarda harcama kalemi olarak yer almamış olan giderler, kamu harcaması sayılmaz. Yani, vergi muafiyeti ve istisnalar, devlet aktifinde meydana gelen azalmalar, özel kişilerin kamu hizmetlerine doğrudan veya dolaylı olarak yaptıkları her türlü yardımlar ve bunlara benzer harcamalar kamu harcaması olarak kabul edilmemektedir (Nadaroğlu, 2000).

\section{Geniş Anlamda Kamu Harcamalarn}

Merkezi idare tarafindan yapılan harcamalar (dar anlamda kamu harcamaları), yerel yönetimlerin yaptığı harcamalar, kamu iktisadi teşebbüslerinin yaptığı harcamalar, sosyal güvenlik kurumlarının harcamaları, vergi harcaması, devlet aktifinde meydana gelen azalmalar ve devlete yapılan bağış ve yardımların toplamından oluşur (Akdoğan, 2005). Geniş anlamda kamu harcaması, devlet bütçesi ile yapılan harcamalara ilave olarak devlet bütçe sistemi dışında yer alan diğer kamu kurum ve kuruluşlarının yaptığı harcamalar ile vergilerde istisna ve muaflık uygulaması nedeniyle devletin almaktan vazgeçtiği vergi gelirlerinin, yani vergi harcamalarının toplamından oluşur. Buna göre, kamu harcamaları sadece devletin değil, diğer kamu kuruluşlarının da nakdi ve ayni olarak doğrudan doğruya yaptıkları harcamaları da kapsamaktadır (Nadaroğlu, 2000).

\section{Kamu Harcamalarmin Sinıflandırılması}

Kamu harcamalarının miktarından çok içeriğinin ekonomi üzerinde yaratacağı etkiler dikkate alınır (Pehlivanoğlu, 2011). Bu sebeple kamu harcamala- 
rını özelliklerine, ekonomik ve sosyal düzen içerisinde meydana getireceği etkilere göre iktisadi sınıflandırmalar yapmak mümkündür. Bu sınıflandırma kamu harcamalarının yapıldığı anda ekonomik ve sosyal hayatta yarattığı etkileri öne çıkarır. Kamu harcamaları iktisadi kıstaslara göre aşağıdaki gibi sinıflandırılmaktadır (Nadaroğlu, 2000; Türk, 2010):

- Reel harcamalar-Transfer harcamaları

- Cari harcamalar-Yatırım harcamaları

\section{Reel Harcamalar ve Transfer Harcamalarn}

Reel harcamalar devletin mal ve hizmetleri satın almak için yaptığı harcamalardır. Reel harcamaların önemli özelliklerinden biri milli gelire yansıyan harcamalar olmasıdır. Yani bu harcamalar milli geliri arttırıc etkiler yaratır. Transfer harcamaları ise ister karşılıklı ister karşılıksız olsun milli geliri değiştirmeyen harcamalardır (Türk, 2010). Diğer taraftan karşlıksız sayılan transfer harcamaları da vardır ki bunlar; gelir dağılımını düzenlemek amacıyla yapılan harcamalardır. Dul, yetim, yaşlılık aylıkları, öğrenci bursları, sübvansiyonlar vb. karşıllğında bir mal veya hizmet alımı olmayan harcamalar transfer harcamalardır. Personel giderleri, mal ve hizmet alımı reel harcamalar iken; borç faizi ödemesi, emekli aylıkları, burs vb. harcamalar transfer harcamalarıdır (Nadaroğlu, 2000).

\section{Cari Harcamalar ve Yatırm Harcamalarn}

Cari harcamaların temel özelliği kamu tüketimiyle ilgili olup sağladıkları faydaların süreksiz olmasıdır. Devletin, kamusal mal ve hizmet üretebilmek amacıyla, mal ve hizmetlere karşı doğrudan bir talep yaratmasıdır. Devletin idari hizmetlerini yerine getirebilmesi için yaptığı cari harcamalar her yıl tekrar edilir; yani devamlı olarak yapılır (Pehlivanoğlu, 2011). Cari harcamaların asıl amacı devletin asli fonksiyonlarının işleyişini sağlamaktır. Devletin ödediği memur maaşları, yolluklar, kırtasiye malzemeleri, kira, su ve elektrik faturaları vb. giderleri cari harcamalar içinde sayılır (Bulutoğlu, 2008). Cari harcamalar mal ve hizmet satın almaya yönelik oldukları için ekonominin makro dengelerini etkileyecek niteliktedir. Özetle faydası o bütçe dönemiyle sınırlı olan ve devamlı yapılan harcamalardır (Nadaroğlu, 2000). 
Yatırım harcamaları üretim kapasitesini artırmaya yönelik ve sermaye birikimi sağlamak amacıyla yapılan harcamalardır. Yatırım harcamaları, üretimi artıran, kaynakların iyi kullanılmasını sağlayan, üretim faktörlerinin verimliliğini olumlu yönde etkileyen, birkaç kez kullanılmakla tükenmeyen ve faydası uzun dönemli mallara yapılan harcamalardan oluşmaktadır (Pehlivanoğlu, 2011). Yollar, yapılar, barajlar, tesisler vb. yatırımlar bu kapsamda değerlendirilmektedir. Yatırım harcamaları milli geliri artırırken, diğer taraftan da istihdam düzeyini yükseltir. Yatırımların milli gelir düzeyini yükseltmeleri çarpan ve hızlandıran etkisiyle gerçekleşir (Bulutoğlu, 2008). Milli gelirdeki artış ile istihdam düzeyinin yükselmesi aynı yönlü kavramlar olması nedeniyle milli gelirin yükselmesi üretim düzeyini, üretim potansiyelini ve istihdam düzeyini de yükseltecektir. Bu sebeple yatırım harcamalarının faydaları uzun yıllara sirayet eder, yatırım harcamaları sürekli ve devamlıdır (Nadaroğlu, 2000).

\section{Yöntem}

Bu çalışmada yükseköğretim harcamalarının bütçe içindeki yerini ve dünyada yükseköğretime ayrılan payı belirlemek amacıyla alanyazın taraması gerçekleştirilmiştir. Alanyazın taraması araştırılan konu hakkında bilgilerin yer aldığı yazılı materyallerin analizini ifade etmektedir (Yıldırım ve Şimşek, 2008).

\section{Bulgular}

\section{Eğitim Harcamalarının Türkiye Bütçesi İçindeki Payı}

Eğitim hizmeti hem kamu hem de özel sektör tarafından üretilen yarı kamusal mal ve hizmet kapsamında ele alınmaktadır. Türkiye'de eğitim harcamaları 2016 yılında 2015 yılına göre \%18,9 artarak 160 milyar 873 milyon TL olmuştur. 2016 yılında bir önceki yıla göre eğitim harcamalarının en çok arttı̆̆ eğitim düzeyleri; \%31,6 ile ortaöğretim, \%20,3 ile yükseköğretimdir. Eğitim harcamalarının, gayri safi yurtiçi hâsıla içindeki payı 2015 yılında \%5,8 iken, 2016 yılında \%6,2'dir. Türkiye'de 2016 yılında yapılan eğitim harcamalarının $\% 74,2$ 'si devlet tarafından finanse edilmiştir. Eğitim harcamaları içerisinde hane halklarının yaptığı harcamaların payı ise $\% 18,8^{\prime}$ dir. 
Devlet kurumlarınca yapılan harcamaların \%29,8'ini (31 milyar 348 milyon TL) yükseköğretim, \%28,1'ini (29 milyar 524 milyon TL) ilkokul oluşturmaktadır. Özel kurumlarca yapılan harcamaların ise \%43,3'ü (11 milyar 613 milyon TL) yükseköğretime, \%32,6's1 (8 milyar 752 milyon TL) ortaöğretime yapılmıştır. Öğrenci başına yapılan eğitim harcaması 2015 yılında 6 bin 382 TL olurken, 2016 yılında ise 7 bin 449 TL olarak gerçekleşmiştir. Öğrenci başına toplam eğitim harcaması bir önceki yıla göre \%16,7 artmıştır. Eğitim harcamalarının 2016 yılında 2015 yılına göre en fazla artış gösterdiği eğitim düzeyi ise $\% 30,7$ ile ortaöğretim olmuş ve bunu $\% 20,2$ ile ilkokul takip etmiştir (TÜİK, 2017).

Tablo 1. 2016 Yılı Finans kaynă̆ı ve eğitim düzeylerine göre eğitim harcamalan (Milyon TL)

\begin{tabular}{|c|c|c|c|c|c|c|c|c|}
\hline \multirow[b]{2}{*}{ Eğitim düzeyi } & \multirow[b]{2}{*}{$\begin{array}{l}\text { Top- } \\
\text { lam }\end{array}$} & \multicolumn{3}{|c|}{ Devlet Harcamaları } & \multicolumn{2}{|c|}{ Özel Harcamalar } & \multirow[b]{2}{*}{$\begin{array}{l}\text { Özel } \\
\text { tüzel } \\
\text { kişilik- } \\
\text { ler } \\
\end{array}$} & \multirow[b]{2}{*}{$\begin{array}{l}\text { Uluslara- } \\
\text { rası Kay- } \\
\text { naklar }\end{array}$} \\
\hline & & $\begin{array}{l}\text { Top- } \\
\text { lam } \\
\text { devlet }\end{array}$ & $\begin{array}{l}\text { Merke- } \\
\text { zi }\end{array}$ & $\begin{array}{l}\text { Ye- } \\
\text { rel }\end{array}$ & $\begin{array}{l}\text { Top- } \\
\text { lam } \\
\text { özel }\end{array}$ & $\begin{array}{l}\text { Hanehalk- } \\
\text { ları }\end{array}$ & & \\
\hline \multirow{2}{*}{ Toplam } & 160 & 119 & \multirow{2}{*}{118520} & \multirow{2}{*}{896} & \multirow{2}{*}{41169} & \multirow{2}{*}{30165} & \multirow{2}{*}{11004} & \multirow{2}{*}{288} \\
\hline & 873 & 415 & & & & & & \\
\hline Okulöncesi & 7699 & 5202 & 5128 & 74 & 2497 & 2073 & 423 & \\
\hline İlkokul & 31568 & 25536 & 25212 & 323 & 6033 & 4984 & 1049 & \\
\hline Ortaokul & 27917 & 20043 & 19703 & 340 & 7873 & 6819 & 1054 & \\
\hline $\begin{array}{l}\text { Ortaöğretim } \\
\text { toplam }\end{array}$ & 38414 & 25334 & 25176 & 157 & 13033 & 9873 & 3160 & 47 \\
\hline Yükseköğretim & 55275 & 43300 & 43299 & 1 & 11733 & 6415 & 5318 & 241 \\
\hline
\end{tabular}

Kaynak: (TÜIK, 2017).

Tablo 1'de yükseköğretime ayrılan payın diğer eğitim seviyelerine göre daha fazla olduğu ve eğitim harcamalarının devlet bütçesinden karşlanma oranının özel harcamalara nazaran yüksek olduğu görülmektedir.

Tablo 2. Yükseköğretimde öğrenci başına düşen eğitim harcaması, 2011-2016

\begin{tabular}{lllll}
\hline Ĕ̈itim düzeyi & Yıl & $\begin{array}{l}\text { Eğitim harcaması } \\
\text { (milyon TL) }\end{array}$ & $\begin{array}{l}\text { Öğrenci başına } \\
\text { yapılan harcama (TL) }\end{array}$ & $\begin{array}{l}\text { Öğrenci başına } \\
\text { yapılan harcama (\$) }\end{array}$ \\
\hline Yükseköğretim & $\mathbf{2 0 1 6}$ & 55275 & 14201 & 4692 \\
& $\mathbf{2 0 1 5}$ & 45937 & 12720 & 4668 \\
& $\mathbf{2 0 1 4}$ & 42366 & 12996 & 5930 \\
& $\mathbf{2 0 1 3}$ & 37895 & 13110 & 6880 \\
& $\mathbf{2 0 1 2}$ & 33674 & 12386 & 6877 \\
& $\mathbf{2 0 1 1}$ & 28942 & 12241 & 7295 \\
\hline
\end{tabular}

Kaynak: (TÜIK, 2016) 
Tablo 2'de eğitim harcamalarının yıllara göre artış gösterdiği görülmektedir. Bununla birlikte 2011 yılında 103'ü devlet üniversitesi olmak üzere 182 yükseköğretim kurumu bulunuyorken 31 Aralık 2017 itibariyle üniversite sayısı 113'ü devlet üniversitesi olmak üzere 182 olmuştur. Yükseköğretim harcamalarındaki artışta üniversitelerinin sayısındaki artışı da etkili olduğu söylenebilir.

\section{Yükseköğretimde Kamusal Harcamalar}

Yükseköğretim için personel çalıştırma, personellerin SGK giderleri, mal ve hizmet alımı, cari transfer harcamaları gibi harcamalar kamusal harcamaları oluşturmaktadır. Yükseköğretimin 2017 yılının ilk 6 ayı için yaptığı harcamalar; personel giderleri olarak 210.645.705 TL, SGK giderleri 38.085.740 $\mathrm{TL}$, mal ve hizmet alımı 1.062.169.904 TL, cari transfer harcamaları 1.549.274.007 TL ve borç verme için yapılan harcama 3.242.687.677 TL'dir (KYK, 2017).

\section{Yükseköğretimde Transfer Harcamaları}

Yükseköğretimde transfer harcamaları, yükseköğrenim gören öğrencilerin toplu taşımadan, devlet tiyatrolarından, okul yemekhanesinden ve devlet yurtlarından çok düşük bedellerle yararlanmaları şeklinde yapılan harcamalardır. Öğrencilere verilen burs, beslenme yardımı (sabah kahvaltısı ve akşam yemeği) memurlara yapılan yemek yardımı ile SGK'ya ödenen emekli ikramiyeleri, ölüm yardımları vb. giderlerden oluşmaktadır. Yemeklerin fiyatı, piyasa fiyatları ortalamasından en az \%35 oranında indirimlidir (KYK, 2017).

Yurtlarda barınan öğrencilere yapılan günlük beslenme yardımı; 11 Eylül 2017 tarihinden itibaren sabah kahvaltısı yardımı 3,50 TL, akşam yemeği yardımı ise 7,50 TL olmak üzere toplam 11,00 TL'dir. Lokanta, kantin, fotokopi-kırtasiye, kuaför, berber çamaşırhane vb. işletmelerde piyasa fiyatlarindan \%25 oraninda daha ucuz hizmet verilmektedir (KYK, 2017). Devletin yaptığı bu harcamalarda kamunun doğrudan kazanç amacı bulunmaz.

Devletin, yükseköğrenim görmekte olan öğrencilerden çalışamadıkları süre içindeki kazançları üzerinden alabileceği vergilerden vazgeçmesi de 
kamusal harcamalar olarak göz önünde bulundurulmalıdır. Vazgeçilen vergiler, öğrencilerin bir yükseköğretim kurumuna devam etmeleri nedeniyle, öğrenimleri süresince kaybedilen brüt kazançlardan kesilecek vergiler toplamını ifade etmektedir. Bu maliyet kamusal vazgeçme maliyeti olarak ifade edilmektedir. Buna göre kamusal vazgeçme maliyeti= Brüt asgari ücret-net asgari ücret $x$ ay olarak şeklinde hesaplanır. 2017 yılı için; bir yıllık kamusal maliyet (vazgeçilen vergi) $(1777.50 \mathrm{TL}-1404.06 \mathrm{TL}=373.44 \mathrm{TL}) \times(12$ ay) $=4481.28 \mathrm{TL}$ olmaktadır. Transfer harcamaları gelir dağılımındaki adaleti sağlamak amacıyla yapılır ve yükseköğretimin gelecekte yaratacağı olumlu etkiyi hedefler.

\section{Burs ve Kredi}

Krediler, ortaöğretim sonrası eğitimin her biçimine erişilebilirliği arttırmak için tasarlanan mali yardımlardır. Öğrenci kredileri yükseköğretim masraflarının bir bölümünü öğrencilere kaydırmak için tasarlanmıştır (Johnstone, 2015). Bu nedenle öğrenci kredileri dünya ülkelerinde yükseköğretimin finansmanının ayrılmaz bir parçası olarak görülmektedir.

Dünya ülkelerinde; ABD, Kanada, İngiltere, İsveç, Norveç, Danimarka, Almanya, Hollanda, Portekiz, Avrupa ülkeleri, Kenya ve Güney Afrika, Şili, Japonya, Kore ve Çin'de öğrencilere kredi sağlanmaktadır. Örneğin İsveç'te 2015 yılında öğrenci finansmanının 40 haftalık bir dönem için ödenen hibe miktarı 28.280 Kron (13.088 TL), kredinin tavan tutarı 71.200 Kron'dur (32.950 TL). Tam zamanlı eğitim alan bireysel bir öğrenci için devlet tarafından desteklenen öğrenci finansmanı toplamı 99.480 Krondur (50.000 TL). Öğrenciler, bu mali desteği en fazla on iki dönem veya altı akademik yıl boyunca alabilmektedir. Kredinin geri ödenmesi bir emeklilik sistemine dayanmakta ve normal durumlarda toplam borç 25 yıl içerisinde veya borçlu 60 yaşına gelmeden ödenmektedir. Böylece verilen kredi tutarı değer kaybetmeden vatandaştan tahsil edilerek kamuya gelir olarak kaydedilmektedir (UKA, 2016). İngiltere'de ve ABD'de ihtiyaç temelli bağışların hızını korumaması ve yükseköğretim maliyetlerinin artmasıyla birlikte federal olarak desteklenen öğrenci kredilerinin toplam hacmi önemli ölçüde artmıştır (Dearden ve dĭğ. 2011). Öğrenci kredisinin ek gelir ihtiyacını sağlamada önemli bir rol oynamaya devam edeceği öngörülmektedir (Johnstone, 2015). 
Burslar; kamu kurumları, üniversiteler, vakıflar ya da özel sektör gibi kaynaklardan yükseköğretim öğrencilerine karşlıksız olarak verilen maddi yardımdır ve dünyanın pek çok ülkesinde öğrenciler için önemli bir finansman kaynağıdır. Ülkemizde belediyeler, kaymakamlıkların sosyal yardımlaşma ve dayanışma vakıfları, farklı okul ve üniversitelere ait vakıflar, dernekler, işverenler veya hayırsever bireyler, başarılı ve maddi desteğe ihtiyaç duyan yükseköğretim öğrencilerine burslar sağlamaktadır.

2016 yllında yurtiçinde ve yurtdışında 1.150 .693 öğrenciye 5.593.073.612,86 TL öğrenim kredisi ödemesi yapılmıştır. 2016 yılında yurtiçinde ve yurtdışında 378.823 öğrenciye 1.841.537.052,86 TL burs ödemesi yapılmıştır. 2016 yılında toplamda 1.529.516 öğrenciye öğrenim kredisi, burs ödemesi yapılmıştır. Burs ve öğrenim kredisi ödemelerinin toplam bütçe giderlerine oranı \%64 olarak gerçekleşmiştir. 2017 yılı için ise KYK tarafından yükseköğretim öğrencilerine öğrenim kredisi verilmesi için ayrilan bütçe başlangıç ödeneği 5.874.649.000 TL'dir. 2017 yılının ilk altı ayındaki harcama 3.242.687.677 TL olmuştur (YURTKUR, 2017).

\section{OECD Ülkelerinde Yükseköğretim Hizmeti}

Dünya ülkeleri temel ekonomileri, kültürleri ve politik sistemleri açısından birbirlerinden oldukça farklı olmalarına rağmen yükseköğretimin finansmanı konusunda ülkeler arasında büyük benzerlikler bulunmaktadır (Johnstone, 2015). Dünyadaki egemen tema, yükseköğretim kurumlarını ve aileleri etkileyen ve neredeyse tüm ülkeler tarafından zorunlu tutulan politika hedeflerini karşılamak için uygulanan ciddi bir kemer sıkma politikasıdır (Johnstone, 2015). Bu kemer sıkma politikasının temelinde; yükseköğretimin, özellikle araştırma üniversitelerinin maliyetli olması, bu maliyelerin ve yükseköğretime kayıtların her yıl artması gibi dünya çapında benzer olan ekonomik gerçekler yatmaktadır (Johnstone, 2015). Artan bu maliyetler ülkeleri; yükseköğretimin kamusal gelirler, aile katkıları ve hayırseverlerin bir kombinasyonu ile finanse edilmesi gerektiği şeklindeki anlayışa yöneltmektedir.

Dünya ülkelerinde yükseköğretimin tamamen kamu kaynaklarıyla finanse edildiği ülkeler; Finlandiya, İrlanda, Almanya, Fransa olarak gösterilebilir. Bu ülkelerde yükseköğretim kamusal maldır. Yükseköğretim; ABD, 
İtalya, Hollanda, Portekiz, Avusturya, İngiltere'de ise yarı kamusal maldır ve öğrenciler bu öğretimin finansmanına katkıda bulunur.

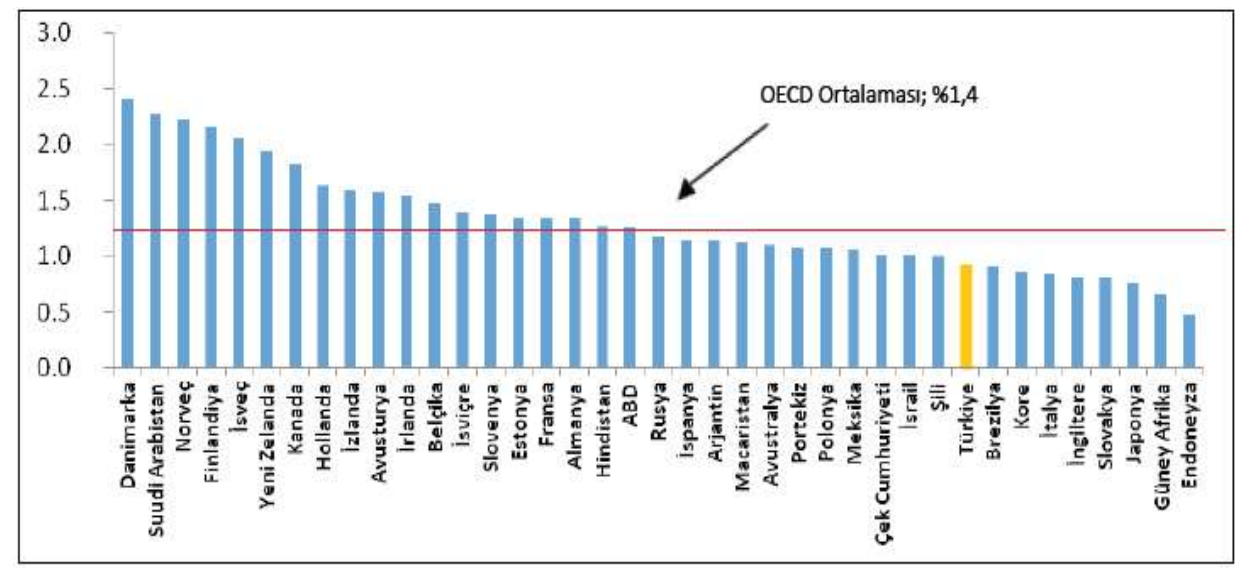

Şekil 1. OECD Ülkelerinde Yüksekögrretim Harcamalarnıı GSYH P-paylarn (Kaynak: OECD Education at a Glance 2012)

ABD'de yükseköğretimin finansmanında öğrencilere değişik seçenekler sunulmaktadır. Özel üniversitelerde ortalama yıllık 17.000\$, iki yıllık devlet yüksekokullarında ortalama yıllık 1500\$ öğrenci katkı payı alınıken eğitimde firsat eşitliğinin sağlanması için federal hükümetler dar gelirli öğrencilere yılda 160 milyar dolar yardımda bulunmaktadır. Doğu Avrupa Ülkelerinde ise genellikle ikili bir sistem uygulanmaktadır. Bu ülkelerde belli bir kontenjana kadar eğitim ücretsiz verilirken kontenjan fazlası öğrenciler için belli bir ücret alınmaktadır. Japonya, Filipinler, Kore ve Doğu ve Güney Asya'da ve Latin Amerika'nın birçoğunda, özel kolejleri ve üniversiteleri teşvik ederek artan yükseköğrenim talebi karşılanmaya çalışılmaktadır. Özel sektörün büyümesi, doğrudan ve dolaylı kamu mali yardımlarıyla teşvik edilmektedir (Johnstone, 2015).

\section{Sonuç}

Yükseköğretim, devletler tarafından vatandaşlarına sunulması zorunluluk arz etmeyen yarı kamusal mal olmasına rağmen ekonomik getirisinin fazla olması sebebiyle devletler yükseköğretim hizmeti vermekte ve bu hizmetin 
yükünü biraz hafifletebilmek adına özel sektörün de desteğini teşvik etmektedir. Dünyanın pek çok ülkesinde de yükseköğretim ağırlıklı olarak kamu sektörünün desteğiyle sürdürülmektedir. Dünya ülkeleri temel ekonomileri, kültürleri ve politik sistemleri açısından birbirlerinden oldukça farklı olmalarına rağmen yükseköğretimin finansmanı konusunda ülkeler arasında büyük benzerlikler bulunduğu görülmüştür. Özellikle eğitim gibi alanlara yapılan harcamaların gelecekte toplumsal gelişimde göstereceği etki de dikkate alındığında yapılan kamu harcamalarının toplum ve ülke üzerinde olumlu etki yaratacağı düşünülmektedir. Devlet tarafından yükseköğretim öğrencilerine yönelik yapılan sosyal transferler, verimsiz transferler ve bütçe kanunundaki adiyla cari transferler olarak ifade edilen burs, kredi gibi harcamalarla sosyal dengenin sağlanması hedeflenmektedir. Söz konusu harcamaların ilk etapta beyhude yapıldığı düşünülse de bu destekler, öğrencilerin yükseköğrenimlerini tamamlamalarına yardımcı olmaktadır. Eğitimli birer birey yetiştirmeye katkı sağlayacağı ve yetişmiş bireylerin de daha sağlıklı ve üreten bir toplum yaratacağını da dikkate alındığında bu harcamaların kısılması ülke gelişimini olumsuz etkileyeceği söylenebilir. Bu nedenle bu tür harcamaların olumlu dışsallık yaratması münasebetiyle bütçe içindeki paylarının her geçen gün artırılması ülkenin gelişmesi ve büyümesi için önemlidir. 


\title{
EXTENDED ABSTRACT
}

\section{Financial Aspects of Unpaid Spending by the State for Higher Education Students}

\author{
Şefika Şule Erçetin - Sait Akbaşlı - Ercan Baysülen \\ Hacettepe University, Ministry of National Education
}

Human investment is of great importance in economic development. The dynamo of economic development is growth and growth requires the efficient use of production factors. The main element that manages and brings together the factors of production is human. In the process of growth, the quantitative and qualitative training of the human factor is the fundamental dynamic of growth and development. For this reason, countries make some expenditures from their own treasures in education in order to make the existing manpower more qualified. While the mentioned expenditures can be made directly in the form of scholarship, education loan, on the other hand, higher education students can benefit from public transportation vehicles, state theaters, school cafeteria and state dormitories at very low prices. These expenditures are called transfer expenditures in economy / finance literature. It is also known that these expenditures did not cause any increase in national income; however, there are two objectives underlying states to make these expenditures. The first one is the protectionism policy brought by the understanding of the social state; the other is to ensure that students complete their education process completely and smoothly with such expenditures. The main element in the subtext of these objectives of the states is that by raising qualified manpower, this manpower provides more qualified contributions to the country's economy after graduation. This contribution called externality in the economy / finance literature; it will have a positive impact in the future with higher education and will eliminate social and production deficits such as possible unemployment or theft.

Education service is handled within the scope of semi-public goods and services produced by both public and private sectors. Higher education is also a semi-public good that does not have to be presented to its citizens 
by states. The state provides higher education services for individuals to receive higher education services due to its high economic return and encourages the private sector to support higher education in order to alleviate the burden of this service. In many countries of the world, higher education is mainly carried out with the support of the public sector.

Although the countries of the world are quite different from each other in terms of their basic economies, cultures and political systems, there are large similarities between countries regarding the financing of higher education. The dominant theme in the world is a serious austerity policy that affects higher education institutions and families, implemented by almost all countries to meet political goals; because higher education, especially research universities, are very costly and the demand for these institutions is increasing every year. This situation leads to the understanding that higher education should be financed through public revenues, family contributions and a combination of philanthropists.

In this study, its place in the higher education budget of expenditures on higher education in Turkey and the world in order to determine the share allocated literature review was conducted. The literature review refers to the analysis of written materials that contain information on the subject being researched. Spending on education in Turkey was 160 billion 873 million TL with an increase of $18.9 \%$ compared to 2015 in 2016. Education levels in which education expenditures increased the most in 2016 compared to the previous year; secondary education with $31.6 \%$ and higher education with $20.3 \%$. It was observed that the share allocated to higher education in 2016 was higher than other education levels, and the ratio of education expenditures covered by the state budget was higher than private expenditures. Countries in which the higher education is financed by public resources in the world countries are Finland, Ireland, Germany, France. It is semi-public goods in the USA, Italy, the Netherlands, Portugal, Austria and England, and students contribute to the financing of this education. Although higher education is a semi-public good that is not obliged to be presented to its citizens by the states, public expenditures are considered to have a positive effect on the society and the country, given the high economic return. It is aimed to achieve social balance through social transfers, inefficient transfers and current transfers in the budget law, such as scholarships and loans, which are expressed as current trans- 
fers. Although these expenditures are thought to be futile in the first place, these supports help students to complete their higher education. Considering that it will contribute to raising educated individuals and that educated individuals will create a healthier and productive society, it can be said that the reduction of these expenditures will affect the development of the country negatively. For this reason, it is important for the country's development and growth to increase its shares in the budget day by day in order to create positive externality of such expenditures.

\section{Kaynakça / References}

Akça, H. (2012). Yükseköğretimin finansmanı ve türkiye için yükseköğretim finansman modeli önerisi. Yönetim Ve Ekonomi, 19(1), 91-104.

Akdoğan, A. (2005). Kamu maliyesi. 10. Bask1, Ankara:Gazi Kitabevi,.

Bulutoğlu, K. (2008). Kamu ekonomisine giriş, 7. Baskı, Ankara:Maliye ve Hukuk Yayınlan,

Dearden, L, Fitzsimons, E, veWyness, G. (2011). The rmpact of tuition fees and support on university participation in the UK. http://hereview.independent.gov.uk/hereview/report/ adresinden erişilmiştir.

Ekinci, E. (2009). Türkiye'de yükseköğretimde öğrenci harcama ve maliyetleri. Eğgitim ve Bilim, 34(154), 119-133.

Hanushek, E. A. (2009a). School policy: Implications of recent research for human capital investments in South Asia and other developing countries. Education Economics, 17(3), 291-313.

Hanushek, E. A. (2009b). The economic value of education and cognitive skills. Handbook of education policy research, 39-56.

Hanushek, E. A. (2009c). School policy: implications of recent research for human capital investments in South Asia and other developing countries. Education Economics, 17(3), 291-313.

Hanushek, E. A. (2016). Will more higher education improve economic growth?. Oxford Review of Economic Policy, 32(4), 538-552.

Hanushek, E. A., ve Wößmann, L. (2007). The role of school improvement in economic development (No. w12832). National Bureau of Economic Research.

Johnstone, D. B. (2003). Cost sharing in higher education: Tuition, financial assistance, and accessibility in a comparative perspective. Sociologický časopis/Czech Sociological Review, 39(3), 351-374 
Johnstone, D. B. (2015). Financing higher education worldwide perspectives and policy options. THF Working Paper, Working Papers Series No.6/2015, University at Buffalo, State University of New York (SUNY).

KYK. (2017). 2017 yll kurumsal mali durum ve beklentiler raporu. http://yurtkur.gsb.gov.tr/Public/Edit/images/KYK/MaliDurumDenetimRapo rlari/2017/2017 Mali Durum Beklentiler Raporu.pdf adresinden erişilmiştir.

Nadaroğlu, H. (2000). Kamu maliyesi teorisi. 11. Bask1, İstanbul: Beta Yayınları.

OECD (2017a), Benchmarking higher education system performance: Conceptual framework and data, Enhancing Higher Education System Performance. OECD Paris.

OECD (2017b). Education at a Glance 2017: OECD indicators. Paris:OECD Publishing. http://dx.doi.org/10.1787/eag-2017-en

Pehlivanoğlu, O. (2011). Kamu maliyesi. Trabzon:Murathan Yayınevi.

Stiglitz, J. E. (1994). Kamu kesimi ekonomisi. İstanbul:Marmara Üniversitesi Yayınları, 2. Baskı.

TÜIKK, (2017). Eğitim istatistikleri. 24.12.2017 tarihinde www.tuik.gov.tr adresinden erişilmiştir.

Türk, İ. (2010). Kamu maliyesi. 8. Baskı, Ankara:Turhan Kitabevi.

Türkmen, F. (2009). Yükseköğretim sistemi için bir finansman modeli önerisi. DPT. http://www3.kalkinma.gov.tr/DocObjects/View/4230/yoksistemi.pdf adresinden erişilmiştir.

UKA, (2016). Status Report 2016: Higher education in Sweden. https://english.uka.se/about-us/publications/reports-guidelines/reports--guidelines/2016-06-16-higher-education-insweden---2016-status-report.html adresinden erişilmiştir.

Yıldırım, A. ve Şimşek, H. (2008). Sosyal bilimlerde nitel araştırma yöntemleri. 6. Baskı, Ankara: Seçkin Yayıncılık.

YURTKUR. (2017). 2016 yll faaliyet raporu. http://yurtkur.gsb.gov.tr/Public/Edit/images/KYK/FaaliyetRaporlar\%C4\%B $1 / 2016$ falliyet raporu 1.pdf

\section{Kaynakça Bilgisi / Citation Information}

Erçetin, Ş. Ş., Akbaşlı, S. ve Baysülen, E., (2020). Devletin yükseköğretim öğrencilerine yönelik yaptığ 1 karşılıksız harcamalarının mali bo-yutu. OPUS-Uluslararası Toplum Araştırmaları Dergisi, 16(28), 1183-1199. DOI: 10.26466/opus.680225 